\title{
EL DERECHO A LA CARIDAD: REPERCUSIONES DE LA TEOLOGÍA CRISTIANA EN LA TEORÍA DE LA PROPIEDAD DE JOHN LOCKE
}

\author{
Juliana Udi \\ Universidad de Buenos Aires (Argentina) \\ Universidad Nacional de Quilmes (Argentina) \\ julianaudi@yahoo.com.ar
}

\begin{abstract}
Resumen / Abstract
Locke, además de justificar un derecho natural a la propiedad privada, también sostiene que todos los hombres tienen un derecho natural a la caridad. En el presente trabajo me propongo defender la hipótesis de que el derecho a la caridad postulado por Locke se explica por la presencia en su teoría de la propiedad de elementos procedentes de la teología cristiana. Cumpliría la función de garantizar que, en el contexto de una economía monetizada donde los individuos son, además, desigualmente industriosos, se cumpla el designio divino de que todos los hombres dispongan de medios para preservarse.

Palabras Clave: Locke, caridad, propiedad privada, derecho a los medios de preservación, cristianismo, teología cristiana.

\section{The Right to CHARITY: Repercussions of CHRISTIAN THEOLOGY ON JOHN LOCKE'S THEORY OF PROPERTY}

Locke, as well as justifying a natural right to private property, also stresses that human beings do have a natural right to charity. My purpose in this paper is to defend the hypothesis that the right of charity postulated by Locke can be explained in terms of the presence of Christian-theological premises in his theory of property. In a monetized economy in which men are unequally industrious, the right to charity guaranties the fulfillment of the divine commandment of human preservation.
\end{abstract}

KEY WORDS: Locke, charity, private property, right to the means of preservation, Christianity, Christian theology.

$\overline{R A}$ En la historia del pensamiento político, John Locke se ganó un lugar de trascendencia, fundamentalmente, como teórico de la limitación del gobierno, la tolerancia religiosa y los derechos de propiedad. En el capítulo 5 de su Segundo tratado diseñó un influyente argumento para explicar cómo puede ser legítimo que un individuo adquiera propiedad exclusiva sobre un bien -en lugar de compartirlo con el resto de la humanidad- sin necesidad del consentimiento de los otros individuos ni de la intervención de una autoridad jurídico-política. Según el argumento desarrollado en ese escrito, cuando un hombre mezcla su trabajo -bien sobre el cual se supone que tiene 
plena propiedad-de manera indiscernible e irreversible con un objeto originariamente común, adquiere sobre ese objeto un derecho exclusivo que merece ser respetado y protegido. Ahora bien, de este punto de partida podría derivarse que a cada individuo le será permitido apropiarse de tantas cosas como sus capacidades, su ambición y su laboriosidad le permitan. Sin embargo, no es esto lo que sostuvo Locke. Por el contrario, postuló dos limitaciones normativas a los actos de apropiación privada: no desperdiciar recursos (ST, §31) y dejar "suficiente y tan bueno" de lo apropiado para los demás (ST, $\S 27)$. Muchos autores restaron importancia al impacto limitativo de estas condiciones y así llegaron a plantear lo que por mucho tiempo fue la interpretación estándar de la teoría lockeana de la propiedad: Locke no solamente sería el teórico paradigmático de los derechos de propiedad privada, quien los dotara de un fundamento natural (el trabajo) y de una validez prepolítica, sino que además sería un teórico de la apropiación privada ilimitada (Strauss 1963; Macpherson 2005; Nozick 1988). En el presente trabajo retomo un tópico abordado por Locke en sus escritos políticos que puede resultar paradójico frente a esta imagen de Locke como teórico de la propiedad privada: la caridad. En el primer apartado expongo y analizo el deber (y el derecho) de caridad tal como aparece formulado en el Primer tratado. En el segundo apartado explicito su basamento justificatorio: el derecho natural a los medios de preservación. En el tercer apartado, retomando (y aplicando al caso de la caridad) algunas consideraciones de Jeremy Waldron (2002) sobre la filiación cristiana del concepto lockeano de igualdad, argumento que el derecho a la caridad de Locke es un efecto de ciertas premisas teológicas que se encuentran a la base de su teoría de la propiedad.

\section{La caridad en el Primer tratado}

Inexplicablemente, la doctrina de la caridad de Locke ha permanecido hasta hoy como un tema apenas tratado ${ }^{1}$. Esto llama la atención si se toman en cuenta los no pocos pasajes del corpus lockeano en los que aparece mencionada o sugerida. En el $\S 6$ del Segundo tratado, Locke plantea que "cada uno debe, cuando su propia preservación no está en juego, preservar al resto de la humanidad tanto como le sea posible". En el $\$ 70$ afirma que todos debemos "caridad y asistencia a los menesterosos" y en el $\$ 93$ se refiere nuevamente a "la caridad que nos debemos unos a otros". En otras obras "menores" de Locke pueden encontrarse referencias similares. En los Ensayos sobre

1 Jeremy Waldron (2002) fue uno de los pocos autores que, sin desarrollar el tema de la caridad, al menos señaló su importancia en el Primer tratado y se refirió al principio de caridad como "una condición mucho más fundamental" que las limitaciones de suficiencia y no-desperdicio (p. 177). John Simmons (1992) dedicó a la caridad un breve apartado del último capítulo de su libro sobre la teoría de los derechos de Locke y se permitió desafiar programáticamente "la persistencia del punto de vista según el cual Locke está desinteresado en los derechos y deberes relativos a la caridad" (pp. 327-336). Sin embargo, ninguno de estos autores indagó a fondo la cuestión. 
la ley natural Locke afirma que todos tenemos el deber de "consolar a nuestro prójimo desahuciado", prestar "asistencia" a "aquellos que se encuentran en problemas" y "alimentar al hambriento" (ELN VII, p. 123). En un texto breve y poco conocido de 1695, titulado "Venditio", Locke sopesa las exigencias de la justicia y las de la caridad, y sostiene que en casos de necesidad extrema esta última debe priorizarse. Asimismo, en sus escritos pedagógicos, Locke destaca la necesidad de enseñar a los niños la liberalidad, que define como "la disposición a compartir de buen grado lo que se tiene" (Thoughts, §110).

Con todo, la alusión más explícita de Locke a la existencia de un deber y un derecho a la caridad aparece en un pasaje del capítulo cuarto del Primer tratado. Allí, refiriéndose a las personas que atraviesan una situación de necesidad extrema, Locke postula la existencia de un deber para con ellas de parte de quienes se encuentran en una mejor situación:

sabemos que Dios no dejó a ningún hombre tan a merced de otro como para que éste pueda dejarlo morir de hambre si le place. Dios, Señor y Padre de todos, no ha dado a ninguno de sus hijos tal propiedad sobre su porción particular de las cosas de este mundo, sino que ha concedido a su hermano necesitado un derecho sobre el excedente de sus bienes, de forma que, en justicia, no se le pueden negar cuando sus necesidades apremiantes los reclamen. Y, en consecuencia, ningún hombre pudo nunca tener un poder justo sobre la vida de otro, por derecho de propiedad de la tierra o de otras posesiones. Y siempre será pecado que un hombre de posición deje perecer en la necesidad a su hermano por no darle algo de lo que mucho tiene. Así como la justicia otorga a cada hombre un título sobre el producto de su honesta industria y las legítimas adquisiciones que sus antecesores le legaron, de modo análogo la caridad da a todos los hombres un título sobre lo que le sobra a los que mucho poseen, para mantenerlos alejados de la necesidad extrema, en tanto carezcan de medios para subsistir de otra manera (FT, §42).

Es usual concebir a la caridad como una práctica supererogatoria, esto es, situada más allá del orden de lo obligatorio. Paradójicamente, Locke la considera como el correlato de un derecho a recibir de otro lo necesario para subsistir (en casos extremos donde exista riesgo cierto de morir por inanición, sed o falta de cobijo). Dice Locke: "Dios, Señor y Padre de todos, no ha dado a ninguno de sus hijos tal propiedad sobre su porción particular de las cosas de este mundo, sino que ha concedido a su hermano necesitado un derecho sobre el excedente de sus bienes" (FT, §42, énfasis añadido). Entonces, la caridad tendría, para Locke, el estatus de un derecho-reclamo [claim-right] en el sentido restringido especificado por Wesley Hohfeld (1923): otros tienen un deber correlativo de permitir que el titular del derecho pueda ejercerlo (p. 38).

Según el pasaje citado, el deber de caridad obliga a todos los propietarios de algún tipo de excedente. Locke no aclara que alcance solo a los terratenientes y esta omisión permite especular con que, para estar obligado por el principio de caridad, basta con poseer un excedente de bienes de consumo. Locke da a entender que el deber de caridad obliga a los que tienen bienes por encima de un umbral determinado, de forma tal que no se aplica a todos los que tienen "algún excedente" sino solo a los que tienen 
uno especialmente cuantioso. Las expresiones "hombres de posición" u hombres "que mucho poseen" parecen aludir a una condición socio-económica privilegiada. En otros pasajes del Primer tratado, Locke sostiene que la caridad confiere a los necesitados un derecho sobre el "excedente" o la "abundancia" de bienes que otros poseen y que quienes trabajaron para adquirir propiedades tienen derecho a "una preservación confortable de sus vidas" (FT, §87, énfasis añadido). Todos tienen derecho a "subsistir", pero también a "gozar de las comodidades de la vida" (FT, §97). Probablemente, el excedente que Locke tiene en mente como afectable por las demandas de caridad equivale a toda posesión que esté por encima del umbral de lo requerido no solo para la mera preservación, sino para una preservación acompañada de un mínimo confort. Esto significa que los propietarios pueden conservar todo aquello que necesitan para satisfacer sus propias necesidades (y las necesidades presentes y futuras de las personas a su cargo) más un suplemento razonable de modestas comodidades. (Al margen de esto, obviamente pueden conservar todo aquello que no sea necesario para satisfacer las necesidades de los pobres).

En cuanto a los potenciales beneficiarios del principio de caridad, éste apunta a cubrir las necesidades básicas de un grupo bien delimitado de individuos. Una condición es que los beneficiarios sean personas que se encuentren atravesando una situación de "necesidad extrema", esto es, que ponga en peligro su subsistencia. Sin embargo, la necesidad es conditio sine qua non pero no suficiente para merecer la caridad de los congéneres. Al requisito de extrema necesidad, Locke añade la condición adicional de que la persona necesitada "carezca de medios para subsistir de otra manera". En otras palabras: un indigente, para beneficiarse de la caridad lockeana, debe estar impedido de trabajar, sea por una incapacidad física o intelectual, sea por falta real de empleo.

Por último, Locke da a entender que el deber de caridad es un deber positivo. Es cierto que algunos pasajes aislados podrían hacer pensar en el principio de caridad como un deber meramente negativo, que exige solo una abstención o limitación del propio actuar en favor de los otros. Es el caso de aquellos pasajes en los que Locke se refiere a la ley fundamental de la naturaleza, de la que emanan en definitiva todos los derechos y deberes naturales y, por lo tanto, también el deber de caridad. En el $\S 6$ del Segundo tratado, Locke introduce el contenido de dicha ley. La formulación completa de la ley natural fundamental comprende dos preceptos de maximización jerarquizados de manera tal que el requerimiento que establece el segundo solo adquiere fuerza obligatoria en tanto la exigencia que impone el primero se halla plenamente satisfecha. El primero exige maximizar la propia preservación. El segundo prescribe maximizar la preservación de la humanidad en su conjunto. Al referirse a este deber, que recae sobre todo ser racional, de preservar a la humanidad en su conjunto -aunque sin referirse a la cuestión de la caridad-Locke parece sugerir que éste impone un deber negativo de no daño al afirmar que:

a menos que sea para hacer justicia con quien haya cometido una trasgresión, [un hombre] no puede quitarle la vida a otro ni producirle un daño, ni menoscabar lo que contribuya a la preservación de su vida, libertad, salud, miembros o bienes (ST, §6, énfasis añadido). 
En este sentido, podría pensarse que el deber de caridad -que se basa en lo mandado por la ley natural fundamental- exige a un individuo no retener el socorro que Dios le exige que preste ante las necesidades ajenas. Sin embargo, el apartado 42 del Primer tratado muestra que el deber de caridad tiene un lado positivo, esto es, que implica que los propietarios de excedentes deben hacer algo en favor de los indigentes, "darle[s] algo de lo mucho que tiene[n]" (énfasis añadido). En particular, que se les debería dar alimento, bebida y abrigo - pues la falta de cualquiera de estas tres cosas puede ser causante de muerte. En el séptimo de los “Ensayos sobre la ley natural” titulado “¿Es perpetua y universal la fuerza obligatoria de la ley natural? Sí" confirma esta idea de que el deber de caridad lockeano es un deber positivo que implica la realización de un "acto exterior" [outward performance] como es "la provisión de alimento a los que sufren hambre" (ELN VII, p. 123), ejemplo con el que Locke reconoce que el socorro del prójimo exigido por la ley natural implica algo más que un mero "hacerse a un lado" para que el pobre pueda satisfacer sus necesidades sirviéndose de lo que un propietario posee legítimamente.

El séptimo de los Ensayos sobre la ley natural de Locke permite, además, precisar el estatus normativo del deber de caridad y la índole de sus exigencias en términos de una clasificación sui generis propuesta por Locke ${ }^{2}$. En ese ensayo, Locke califica al deber de caridad como un deber (i) no permanente u ocasional, (ii) universal y (iii) positivo. Parte de la observación de que en muchas culturas no se cumple con los preceptos emanados de la ley natural y de que lo que en una comunidad es considerado como un deber derivado de la ley natural, no es concebido como tal en otra (ELN VII, p. 121). En este sentido, reconoce Locke, no todos los deberes emanados de la ley natural tienen un alcance perpetuo y universal -entre ellos, el deber de caridad. Para dar cuenta de ello traza una distinción entre ley natural y "preceptos" o "decretos" de la ley natural o, dicho en otros términos, entre la fuerza obligatoria [binding force] de la ley natural y la exigencia concreta que impone la ley de hacer o abstenerse de hacer algo. Según Locke, la fuerza obligatoria de la ley natural es, en primer término, perpetua, porque no existe ni puede existir un lapso de tiempo que se sustraiga a la misma. Es, además, universal, dado que obliga a todos los hombres, en tanto que seres dotados de razón, sin excepción ni distinción de rangos o funciones: vale tanto para el rey como para el súbdito, para el padre tanto como para el hijo, para el noble tanto como para el plebeyo (ELN VII, p. 125). Pero lo mismo no puede afirmarse de todos los "preceptos" o "decretos" particulares emanados de la ley de la naturaleza. Existen algunos casos -observa Locke- en los que la obligación de realizar la acción (o abstención) exigida por la ley depende de que se den determinadas circunstancias que los hacen entrar en vigencia. Los preceptos quedan así divididos en preceptos "absolutos" o "constantes" (aquellos cuya operatividad no está sujeta a condiciones de tiempo y forma) y preceptos "condicionados" o "no permanentes" u “ocasionales" (aquellos que sí lo están). Algunas conductas -como el robo y el homicidio-siempre están prohibidas, y hay sentimientos

2 La importancia de este ensayo a los efectos de precisar mejor el estatus que Locke confiere al deber de caridad me fue sugerida por Kuschnir (2007). 
que siempre debemos experimentar hacia los demás. Pero hay preceptos emanados de la ley natural que no se aplican de manera continua. Por ejemplo, las exigencias de "rendir culto a la divinidad", "consolar a un vecino necesitado", "ayudar a alguien envuelto en problemas" o "proporcionar alimento a los que padecen hambre" no se aplican de manera permanente (ELN VII, p. 123). No estamos obligados a dar refugio y alimento a todos y cada uno de los hombres que nos rodean en todo momento y sea cual fuere nuestra situación personal, sino solo cuando la desgracia de un hombre pobre así lo amerita y cuando, al mismo tiempo, nuestra propiedad proporcione medios suficientes para practicar la caridad (ELN VII, p. 123). Para que el deber de caridad entre en vigencia deben verificarse, entonces, dos condiciones fácticas:

1. que la necesidad de quien reclama la caridad sea tal, que haga urgente la ayuda;

2. que otra persona disponga de algún tipo de excedente para transferir o dejar a disposición de quien lo necesita.

Por otra parte, además de que no todas las exigencias derivadas de la ley natural se aplican de manera permanente, tampoco todas lo hacen de manera universal. Algunos preceptos, como los relativos al robo, los vicios, las calumnias, la religión, la caridad, la fidelidad y cosas semejantes, obligan de manera universal, esto es, para todos los hombres sin distinción. Otros, en cambio, se relacionan con las diferentes condiciones del hombre y las relaciones de unos con otros: unos son los deberes de los reyes y otros muy distintos los de los súbditos. Finalmente, cruzando ambos criterios de clasificación (permanente/circunstancial y universal/especial) el deber lockeano de caridad debe considerarse como un deber no permanente y condicionado, de validez universal.

\section{El fundamento del deber de caridad: el derecho a los medios de preservación}

En la teoría de Locke, los derechos de propiedad y el deber de caridad comparten una misma base justificatoria: el derecho natural a los medios de preservación. Para Locke, los hombres tienen un derecho a los medios de preservación porque, a su vez, tienen la obligación de preservarse. Siendo los hombres obra de Dios, constituyen su propiedad y, por lo tanto, deben subsistir por el tiempo que Él disponga, no por el que ellos deseen. Por este motivo, el hombre "está obligado a preservarse a sí mismo, y a (...) preservar al resto de la humanidad tanto como le sea posible” (ST, §6). Como señalé más arriba, la formulación completa de este mandato, la ley natural fundamental, comprende dos preceptos de maximización jerarquizados. Si bien la preservación de la vida propia tiene prioridad, la de los otros viene inmediatamente después, y así el deber de preservar a los otros prima por sobre todos los intereses egoístas "superfluos". Según Locke, todo esto puede ser exigido porque Dios, habiendo dotado al hombre, como a las demás criaturas, de un fuerte deseo de preservación, le dio también los medios para lograr 
ese fin. De este modo, el deber y el derecho que tienen los hombres de preservarse a sí mismos conlleva un derecho a los medios de preservación:

los hombres, una vez nacidos, tienen derecho a su preservación y, consecuentemente, a comida y bebida, y a las demás cosas que la naturaleza provee para su subsistencia (ST, §25, énfasis añadido).

Es evidente que el derecho a los medios de subsistencia tiene que implicar, en última instancia, un derecho a consumir y usar recursos de primera necesidad. De otro modo, no cumpliría con su propósito de garantizar la preservación de la humanidad. Algunos autores, apoyándose en una lectura literal de un pasaje del Segundo tratado, van más lejos y sostienen que el derecho a los medios de preservación se identifica con este derecho de consumo ${ }^{3}$. Desde esta óptica, existirían tres caminos paralelos para actualizar el derecho a los medios de preservación: el trabajo, la caridad y la herencia (Tully 2006, p. 131). Esto implica considerar que para Locke el derecho que cada uno tiene a consumir comida y bebida en cantidades de subsistencia es independiente del propio trabajo, algo equivocado.

El derecho lockeano a los medios de preservación conlleva un derecho a producir comida, bebida y lo necesario para subsistir, i. e., un derecho a no verse excluido del uso de los recursos naturales comunes provistos abundantemente por Dios y a partir de los cuales puede producirse el sustento. Un derecho inclusivo de este tipo puede concebirse como un derecho de acceso: a ninguno de los titulares de ese derecho se le puede negar el acceso a los recursos naturales comunes necesarios para producir comida, bebida y todo lo demás necesario para vivir. Como, según arguye Locke, producir algo a partir de los recursos comunes provistos por Dios le confiere a uno una propiedad sobre esa cosa, y dado que la propiedad sobre algo claramente involucra un derecho a consumir esa cosa, este derecho a producir también se traduce, de manera mediata, en un derecho a consumir comida, bebida y todo lo demás necesario para la subsistencia. Con todo, este derecho a la producción no debe ser identificado sin más con un derecho al consumo: la conversión de un derecho a los medios de preservación en un derecho de consumo depende de la mediación del trabajo. Es cierto que Dios "les dio el mundo a los hombres en común", pero es más exacto decir que "hizo entrega del mundo para el usufructo de los industriosos y racionales (y el trabajo había de ser el título que les diera derecho a él), no para el capricho y la avaricia de los pendencieros y contenciosos" (ST, $\S 34)$. En circunstancias normales, nadie tiene un derecho directo a comida y bebida; todo el que sea capaz de hacerlo, deberá trabajar (FT, §45). Esto no implica negar que la caridad y la herencia otorguen un derecho sobre los medios de preservación, sino destacar que no constituyen alternativas a la par que el trabajo. Hay una prioridad del trabajo por sobre cualquier otra forma de apropiación privada: esto significa que debe ser agotado como criterio para que otro pueda pasar a considerarse válido. La caridad y la herencia solo son vías operativas cuando un hombre es incapaz de trabajar. Con 
todo, si bien el trabajo tiene un lugar de privilegio en la teoría de la propiedad de Locke que la teoría de la caridad no cuestiona, no es el fundamento último de los derechos de propiedad. Esto explica el hecho de que, en ciertos casos, las exigencias emanadas de la caridad, sin vulnerar los derechos de propiedad que Locke justifica, puedan ser presentadas como más urgentes. ¿Qué sucede con el derecho originario de acceso a los medios de preservación una vez que los hombres, en el contexto de una economía monetizada ${ }^{4}$ comienzan a aplicar su trabajo a los recursos comunes para apropiárselos de un modo que excluye a los otros? A mi juicio, el derecho a la caridad es la forma bajo la cual persiste el contenido normativo del derecho a los medios de preservación una vez iniciado el proceso histórico de apropiación privada de la tierra y de los recursos naturales en general.

\section{Repercusiones de la teología cristiana en la teoría de la propiedad de Locke}

A partir del análisis del apartado 42 del Primer tratado hemos visto que Locke afirma la existencia de un derecho natural a la caridad. Mi hipótesis es que, en definitiva, ello responde a la presencia de algunos elementos procedentes de la teología cristiana en la teoría de la propiedad de Locke. El capítulo quinto del Segundo tratado, tomado aisladamente, puede parecer dirigido a legitimar la "posesión desproporcionada y desigual de la tierra" que inevitablemente genera el trabajo una vez que se introduce el dinero. Pero la teoría del derecho natural que sirve de marco tanto a la teoría de la propiedad de Locke como a su doctrina de la caridad exige velar por la preservación de todos los hombres, aun de los "no industriosos y racionales". Y esta teoría del derecho natural tiene una dimensión teológica: la concepción de la ley natural como un conjunto de mandamientos divinos es el fundamento teológico-filosófico que anima toda la teoría política de Locke, incluida su teoría de la propiedad. Dios, que creó a todos los hombres iguales y les entregó en común los recursos naturales, lo hizo con el propósito de que todos, sin excepción, preserven su vida. Ningún estado de cosas resultante de las acciones de los hombres que se desvíe de esta pauta igualitaria mínima es compatible con este axioma teológico de partida. Como argumentaré a continuación, dentro de esta concepción, el derecho a la caridad cumple la función de garantizar que, en el contexto de una economía monetizada donde los individuos son, además, transformadores desigualmente eficientes de trabajo en bienes propios, se cumpla el designio divino de que todos los hombres dispongan de medios para preservarse.

Locke se mostró interesado en la doctrina cristiana a lo largo de toda su obra (cfr. Waldron 2002, p. 12). En La racionalidad del cristianismo insiste en que la mayoría de los hombres no puede comprender las exigencias de la ley natural sin la

$4 \quad$ Es decir, una economía en la que es posible apropiarse de más de lo que uno puede consumir sin desperdicio. 
ayuda de las enseñanzas y los ejemplos de Jesús. En el Primer tratado argumenta de modo recurrente en base a las Escrituras y, en ocasiones, también lo hace en el Segundo tratado. En gran medida, el recurso a los argumentos bíblicos está ligado al propósito polémico que guía sus Dos tratados sobre el gobierno: refutar la teoría que Filmer expone en Patriarcha, la cual, apoyándose en cierta interpretación del texto bíblico, postula la desigualdad de los hombres. Para oponerse a Filmer, Locke necesita probar que, del mismo modo que la razón, las Escrituras tampoco "nos han sometido a la voluntad ilimitada de otro" (FT, §4). No obstante, como observa Waldron (2002), resulta sugerente que Locke destine todavía mucho más espacio a exponer pasajes del Antiguo Testamento que el que Filmer les destina en los argumentos que Locke dice estar tratando de refutar (pp. 16-17).

Este papel de la religión en la filosofía política de Locke no pasó inadvertido entre los intérpretes de Locke. John Dunn (1969) hace notar que todo el argumento de los Dos tratados está "saturado de presupuestos cristianos" (p. 99) y afirma lo siguiente:

Puede que ni Jesucristo (ni San Pablo) aparezcan en persona en el texto de los Dos tratados, pero su presencia apenas puede ignorarse cuando nos enfrentamos con la igualdad normativa de todos los hombres en virtud de su pertenencia a una misma especie (p. 99).

Edward Andrew (1988) también destacó la influencia religiosa en el pensamiento político de Locke e incluso señaló como una característica “curiosa" del pensamiento liberal contemporáneo su aceptación de la teoría política lockeana unida a un simultáneo rechazo del fundamento teológico-filosófico en el que se apoya (pp. 5-6).

Como observa Waldron (2002), en el corpus maduro de Locke, el cristianismo se expresa, fundamentalmente, bajo la forma de una teoría de la igualdad. Según Locke, Dios creó a los hombres en "un estado de igualdad, en el que todo poder y jurisdicción son recíprocos, y donde nadie los disfruta en mayor medida que los demás" (ST, §4). Este postulado de la igualdad básica de los hombres no tiene el estatus de "una preferencia o una regla empírica de prudencia; tampoco el de un «dictado de la razón»", como las leyes naturales de Hobbes. En cambio, Locke confirió a la idea de igualdad básica

el fundamento más poderoso que se le puede dar a un principio: la consideró un axioma de la teología, entendido como la verdad más importante sobre Dios y su relación con el mundo en lo que respecta a las implicancias sociales y políticas de su creación de la persona humana (Waldron 2002, p. 6).

Según Waldron, en la teoría de Locke esta idea de igualdad básica cumple una doble función. En primer lugar, opera como una premisa sobre la que se apoya toda su teoría política. En segundo lugar, funciona como "límite teórico" que asegura que las derivaciones que se siguen de las premisas de la teoría no se desvíen y continúen siendo plenamente consistentes con el concepto de que las criaturas racionales son iguales entre sí (Waldron 2002, p. 151).

A mi juicio, las dos funciones de la igualdad que Waldron detecta en la teoría de Locke se ponen de manifiesto en su abordaje de la propiedad y la caridad. Más arriba 
señalé que los derechos de propiedad y el deber de caridad comparten una misma base justificatoria: el derecho natural a los medios de preservación. Este derecho se deriva de la idea cristiana de igualdad y de la concepción de la ley natural como expresión de la voluntad divina. Los hombres son criaturas de Dios y deben subsistir por el tiempo que Dios disponga: están obligados a preservarse a sí mismos y a preservar al resto de la humanidad tanto como les sea posible (ST, §6). Esto puede ser exigido porque Dios, además de haber dotado al hombre de un fuerte deseo de preservación, le dio los medios para lograr ese fin. De este modo, el deber y el derecho que tienen los hombres a preservarse conlleva un derecho a los medios de preservación. La manera en que Dios ordenó que este derecho sea ejercido es a través de la aplicación del trabajo a los recursos naturales que puso a disposición de los hombres. A su vez, el deber de caridad oficia como una suerte de reaseguro para que todos los hombres -incluidos los incapaces de apropiarse de recursos por cuenta propia-, en tanto que criaturas de Dios, tengan garantizado el acceso a los medios de preservación. Los hombres nacen iguales y, originariamente, tienen todos el mismo derecho a acceder a los medios para cumplir el mandato divino de preservarse. En el marco de la teoría de la propiedad de Locke, esta igualdad se encarna en el derecho natural que todos tienen a los medios de preservación (la igualdad como premisa). Pero si las cosas se desvían de esta pauta y, por ejemplo, por ejercer diferentes grados de laboriosidad, algunos hombres llegan a apropiarse de mucho más de lo necesario mientras que otros no acceden siquiera a lo indispensable para mantenerse con vida, el ideal de igualdad reaparece como "límite teórico" bajo la forma del deber de caridad.

Cabe aclarar que, desde la perspectiva de Locke, el hecho de que la caridad sea una virtud cristiana no implica que no pueda ser obligatoria. Por el contrario, en $L a$ racionalidad del cristianismo, Locke sostiene que los filósofos tienen que ser capaces de mostrar que una virtud como la caridad es algo más que una buena idea; y que solo los mandamientos de Cristo, el Legislador, pueden presentarla directamente como obligatoria (RC 141:6). Es cierto que, desde el punto de vista de Locke, no todos los mandatos de Jesús pueden o deben ser exigidos coactivamente por el Estado. El mandato cristiano más fundamental es creer en Jesucristo como el Mesías (Locke consagra la mayor parte de La racionalidad del cristianismo a sostener que nada más se necesita para la salvación) y en la Carta sobre la tolerancia, Locke ofrece dos razones para sostener que ese mandato no puede ni debe exigirse por medio de la coacción: (i) la creencia no está sujeta a la voluntad (y la coerción se ejerce sobre la voluntad); (ii) lo que una persona crea (por ejemplo, que Jesús es el Mesías) no afecta el bienestar de ningún otro (pp. 41-42). Con todo, este no parece ser el caso de la virtud cristiana de la caridad, la cual, desde la perspectiva de Locke, sí puede considerarse obligatoria. En la medida en que el mandato cristiano de la caridad se refiere a las acciones de los hombres y no a sus creencias, puede ser considerado obligatorio. Cuando Locke se refiere a la diferencia entre lo que Cristo exige creer y lo que exige hacer, cita la exigencia de caridad que aparece en la parábola del juicio final (la del pastor que separa las ovejas de los cabritos) en Mateo 25:31-46 -alimentar a los hambrientos, dar bebida a los sedientos, acoger a los sin techo y visitar a los que están en prisión-como principal ejemplo de lo que estamos obligados a hacer, por oposición a aquello que se espera que creamos (RC 127). 
En suma, la teoría lockeana de los derechos se encuentra firmemente asentada en el teísmo cristiano y solo resulta completamente inteligible en el marco de la concepción lockeana de la ley natural como expresión de la voluntad divina. Los derechos naturales -emanados de la ley natural y, por tanto, de Dios- encierran las condiciones necesarias para proteger y preservar nuestras vidas. En virtud de estas leyes, los hombres tienen derecho a la propiedad en sentido amplio (vida, libertad y bienes) y, en virtud de estas leyes, también tienen deberes, y sus libertades y derechos se ven limitados. Porque son criaturas de Dios, los hombres libres y, porque son criaturas de Dios, no pueden alienar su libertad completa e irreversiblemente -como en el caso de un contrato de esclavitud-ni suicidarse (ST, §23). Como criaturas de Dios, los hombres pueden adquirir derechos de propiedad aplicando su trabajo a los recursos naturales que Dios les legó para la preservación de sus vidas y, por ello mismo, están obligados a renunciar a una parte de lo que adquirieron si la preservación de la vida de un semejante corre peligro.

\section{Referencias bibliográficas}

Andrew, E. (1988), Shylock's Rights: a Grammar of Lockian Claims. Toronto: University of Toronto Press.

Ashcraft, R. (1987), Locke's Two Treatises of Government. London: Allen and Unwin.

Dunn, J. (1969), The Political Thought of John Locke. Cambridge: Cambridge University Press.

Filmer, R. (2004), "Patriarcha or The Natural Power of Kinges Defended against the Unnatural Liberty of the People", Patriarcha and Other Writings. J. P. Sommerville, ed. Cambridge: Cambridge University Press.

Hohfeld, W. N. (1923), Fundamental Legal Conceptions as Applied in Judicial Reasoning and Other Legal Essays. New Haven: Yale University Press.

Kuschnir, A. (2007), "Derecho de propiedad y deber de caridad en John Locke", Misantropía, filantropía, apatía. P. Hunziker y N. Lerussi, comps. Córdoba: Brujas.

Locke, J. (1963), "The Reasonableness of Christianity, as Delivered in the Scriptures", pp. 1-158, The Works of John Locke in Ten Volumes. A New Edition, Corrected. Reimpresión de la edición de 1823 de Th. Tegg. Vol. VII. London: Scientia Verlag Aalen. (Abrevio "RC" e indico número de parágrafo. Las traducciones son propias).

Locke, J. (1968), "Some Thoughts Concerning Education", The Educational Writings. J. L. Axtell, ed., Cambridge: Cambridge University Press. (Abrevio "Thoughts" e indico número de parágrafo. Las traducciones son propias).

Locke, J. (2004), "Essays on the Law of Nature", Political Essays (pp. 79-133), M. Goldie, ed. Cambridge: Cambridge University Press. (Abrevio "ELN" e indico número de página. Las traducciones son propias). 
Locke, J. (2004), "Venditio", Political Essays (pp. 339-343). M. Goldie, ed. Cambridge: Cambridge University Press.

Locke, J. (2008), "First Treatise", Two Treatises of Government (pp. 141-263). P. Laslett, ed. Cambridge: Cambridge University Press. (Abrevio "FT" e indico número de parágrafo. Las traducciones son propias).

Locke, J. (2008), "Second Treatise", Two Treatises of Government (pp. 265-48). P. Laslett, ed. Cambridge: Cambridge University Press. (Abrevio "ST" e indico número de parágrafo. Las traducciones son propias).

Locke, J. (2010), “A Letter Concerning Toleration”, A Letter Concerning Toleration and Other Writings. M. Goldie, ed. Indianapolis: Liberty Fund. (Abrevio "Letter". Cito indicando número de página).

Macpherson, C. B. (2005), La teoría política del individualismo posesivo. De Hobbes a Locke. J. R. Capella, trad. Madrid: Trotta.

Nozick, R (1988), Anarquía, Estado y utopía. México: Fondo de Cultura Económica.

Simmons, J. (1992), The Lockean Theory of Rights. Princeton: Princeton University Press.

Strauss, L. (1963), Natural Right and History. Chicago: University of Chicago Press.

Tully, J. (2006), A Discourse on Property. John Locke and his adversaries. Cambridge: Cambridge University Press.

Waldron, J. (2002), God, Locke, and Equality. Christian Foundations in Locke's Political Thought. Cambridge: Cambridge University Press. 